\title{
Assessing Electric Vehicles Battery Second Life Remanufacture and Management
}

\author{
L1. Canals Casals* and B. Amante García \\ Universitat Politècnica de Catalunya, Spain \\ *Corresponding Author: lluc.canals@upc.edu
}

Received 1 May 2016; Accepted 29 May 2016;

Publication 4 August 2016

\begin{abstract}
Electric cars are entering into the automotive market. However, their prices are still expensive mostly due to the battery cost. Additionally, electric vehicle batteries are considered not useful for traction purposes after they have lost a $20 \%$ of its capacity. Having still an $80 \%$ of its capacity, these batteries may work on stationary applications with lower requirements than electric mobility.

In order to recover part of the battery costs came out the idea of giving batteries a second life. Nonetheless, before its reuse, these batteries should follow a transformation process that, although valuable, it is not simple. They should be collected, checked and adapted, if necessary, to their new application requirements. Nowadays, each car manufacturer has its own battery partner using a particular cell shape and chemistry. Additionally, each battery has different module configurations and electronic control parameters and equipment. Moreover, each battery model has a particular refrigeration system in the final packaging that forms the whole battery. All these aspects put the reusability of electric vehicle batteries into a narrow path where a bad step could lead to business collapse. This study shows some of the difficulties and issues that should be taken into account when managing second life battery businesses.
\end{abstract}

Keywords: Electric vehicle, lithium ion, batteries, second life, reuse.

Journal of Green Engineering, Vol. 6, 77-98.

doi: 10.13052/jge1904-4720.614

(c) 2016 River Publishers. All rights reserved. 


\section{Introduction}

The entrance of the Electric Vehicle (EV) into the automotive market is constantly increasing since the last decade [1] and it is expected to capture a relevant part of the market even in the worst scenario [2]. As an example, during the last years in Spain, 15 different car manufacturers (Figure 1) gave licenses to 18 different EV models. However, EV has some drawbacks to overcome, like the price and the short autonomy range [3].

Indeed, the EV entrance into the market is environmentally envisaged, but it also comes with threats and challenges for the electricity grid and infrastructure. Fast charge, peaks of electricity consumption, charging points distribution, local service transformers overheating and risks on secondary service lines are just a few of these future problems to be solved $[4,5]$. Fortunately, energy storage systems are often presented as possible solutions to these problems, providing services like load levelling, peak shaving, frequency regulation or sudden shut down support among others [6].

Since now, batteries were not considered for grid services for several reasons. In the past, the principal handicap was the low progress in the state of technology, now that Lithium ion (Li-ion) batteries are reaching good performance results it is their high price that restrain their entrance into ancillary grid services.

Three key factors may help Li-ion batteries to reach economic competitiveness:

- New Li-ion batteries are experiencing a considerable and sustained price reduction because of increasing mass production. It is expected that prices will reduce to half within the next ten years [7].
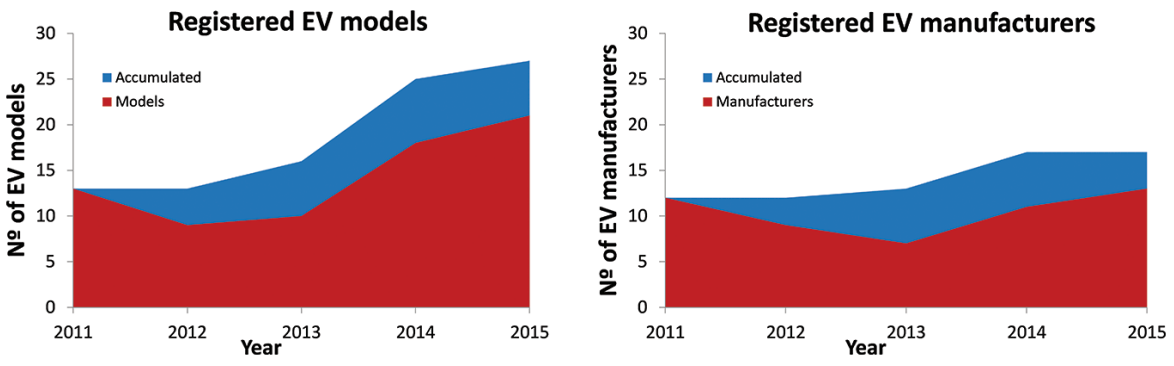

Figure 1 Evolution of the EV models licensed in Spain (Left) and evolution of EV manufacturers (Right). 
- Continuous electricity price increase.

- Future availability of EV batteries ready to reuse.

It occurs that EV batteries are considered not useful for traction purposes after they have lost a $20 \%$ of its capacity and they should be retired from the car. Then, as these batteries still have an $80 \%$ of its initial capacity, they could be used as energy storage systems for the aforementioned solutions [8]. Therefore, what was a problem from the car point of view could be an opportunity from the electricity services side. In fact, some companies are trying to demonstrate their performances and functional benefits with diversity of projects even though the first approaches do not point towards huge revenues [9]. This is when the circular economy and the $2^{\text {nd }}$ life of battery management enter into play.

This study presents different aspects concerning the reuse of EV batteries, such as State of Health ( $\mathrm{SOH}$ ) assessment, different technologies and forms, communications system and Battery Management System (BMS) among others. Moreover, the study analyses different alternatives to confront battery variability, making special attention to the main aspects to take into account before starting up remanufacture businesses.

\section{Battery Collection}

The first aspect to consider is the origin of these batteries. In fact, used EV batteries do not come from a factory as most products normally do; they come from old cars spread all over the world. Therefore, the collection of batteries from old cars is something to deal with. Cars should normally finish their lives in Authorized Treatment Centres (ATC), where they are dismantled. Some parts will be sold as spare parts, others will be recycled and batteries should be sent to the remanufacturing plant.

Another important issue to consider is the inherent danger when working with batteries. A discharged Li-ion battery is not an empty battery. Indeed, Li-ion batteries have security voltage limitations to ensure a stable working range, leaving an unusable remaining capacity. Therefore, when an EV battery is discharged it still has more than $230 \mathrm{~V}$ and plenty of power to deliver. Additionally, it is impossible to know its state of charge (SOC) without specific electronic equipment. Consequently, safety is essential when manipulating these items. EV batteries normally use Lithium ions to transport electrodes from anode to cathode and vice versa. Lithium is a very reactive element being one of the reasons that pushed to classify this type of batteries as dangerous 
goods [10]. This classification causes non-trivial transportation and packaging management, detailed in $[11,12]$, that should be taken into account when calculating transportation costs and equipment required.

Additionally, it is important to identify who is responsible of this battery. European directive 2006/66/EC states that a company putting a battery into the market is responsible of its management at the end-of-life. In the case of EVs, it corresponds to the car manufacturer. However, when dealing with $2^{\text {nd }}$ life EV batteries it is not clear where the responsibility falls to because the battery was already in the market. Hence, the corresponding institutions on each country should regulate this issue.

The easiest way to proceed with the battery collection would be if car manufacturers carry it out by themselves. Nonetheless, as car manufacturers have contracts with Integrated Management Systems (IMS), companies in charge of all component waste management, it could be one of these companies doing the collection. Other solutions could be, for example, that the remanufacturing company registers itself as an IMS and seals an agreement with car manufacturers and ATCs; or that ATCs build a remanufacture plant; or even that car manufacturers get prepared to remanufacture the batteries in-house, recovering batteries by themselves. In fact, there are many options and alternatives.

\section{Battery Variability}

The next barrier to deal with is the diversity between batteries. As presented in Figure 1, there are plenty of electrified models from almost all car manufacturers. Indeed, most car brands have a partnership or specific agreement with battery manufacturers. Moreover, each battery manufacturer is specialized in certain type of cells, designing them to fulfil the requirements provided for each car manufacturer. In addition, these requirements strongly depend on the car model performances. Consequently, there is a vast rainbow of possibilities concerning the different aspects of batteries. Table 1 shows the characteristics of some electrified models conforming this variability. The main differences between EV battery models are: cell chemistry, functional characteristics of the battery, cell type, module dimension, power and capacity of the battery, refrigeration system implemented, battery management algorithms, communication protocol and final packaging. This section presents a short description and discussion of each one of these aspects. 


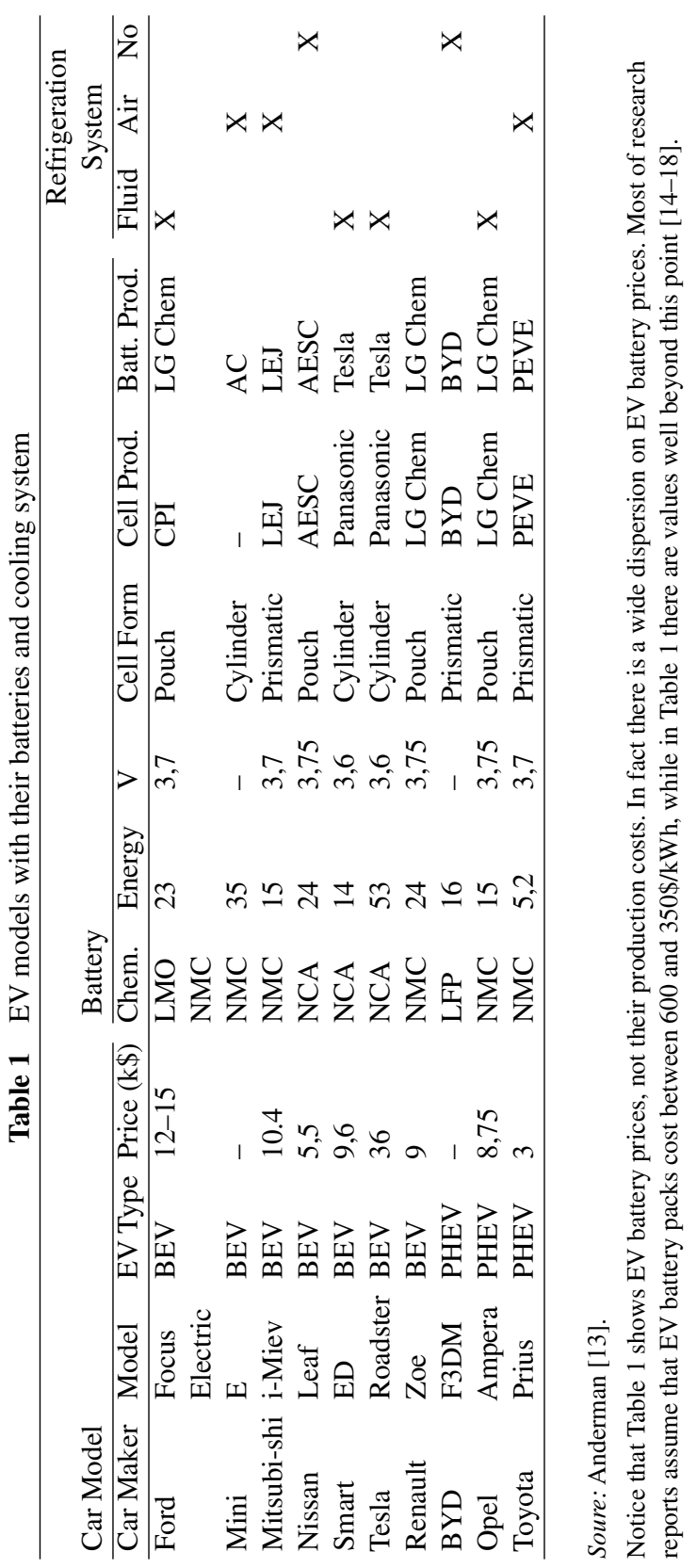


Cell Chemistry: The concept of "Li-ion battery" defines all kind of batteries having lithium ions as the mechanism for electron transportation between electrodes. However, depending on the performances desired, such as high energy density, high power density, safety or lifespan, the selection of anode and cathode materials presents subcategories depending on the elements used to create them. Graphite, Lithium Manganese Oxide (LMO), Lithium Iron Phosphate (LFP), Nickel Manganese Cobalt (NMC), Lithium Nickel Cobalt Aluminium Oxide (NCA), Lithium Cobalt Oxide (LCO), Lithium Titane (LTO) are just some examples of cell chemistries. Each one of them has its own voltage and security limit characteristics [19] as depicted in Figure 2, where cells with higher voltage are the ones having more thermal instability (red line on the left) or lower lifespan (red arrow on the right caused by lithium platting). Technologies have been changing in the recent years, slowly converging to Graphite/NMC for automotive uses [13], but still there are many alternatives used by different car manufacturers, as it is appreciable in Table 1. Battery cells are fabricated adding layers of electrode, electrolyte and separator. The number of layers and its size defines its total capacity.

Functional characteristics: Additionally, knowing that functional exigencies of the vehicle have a direct effect on lifetime [21] and to ensure higher safety standards, car manufacturers added restrictions to the allowed Depth

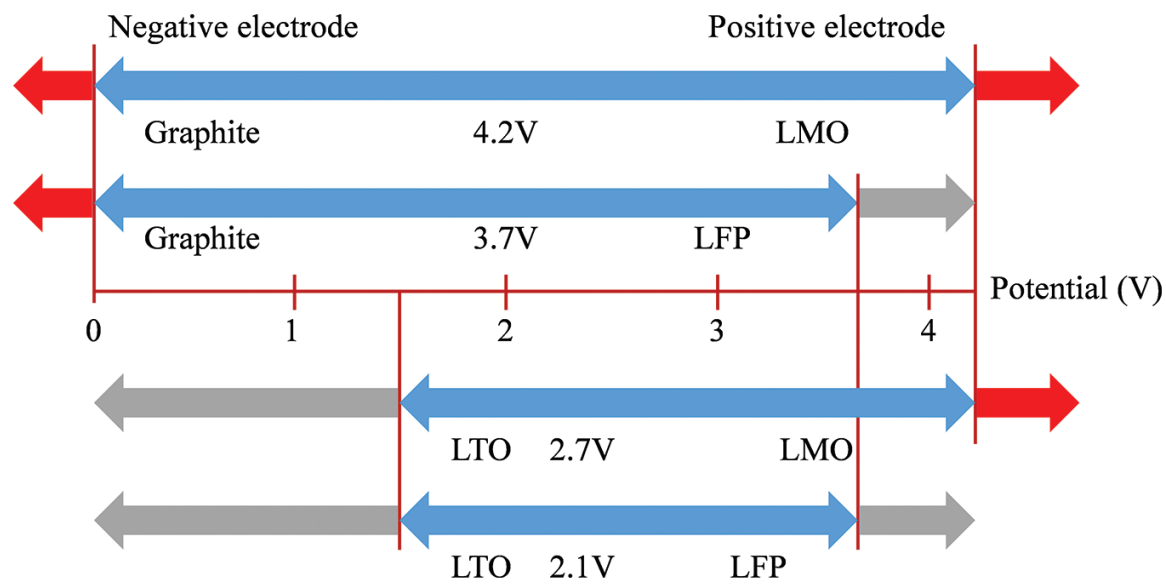

Figure 2 Different lithium cells chemistries potential (V) between electrodes. 
of Discharge (DOD) by changing voltage limits depending on the objectives of longer life guaranties or higher performances. These additional restrictions affect the available capacity of the battery and increase the battery market variability.

Cell Type: There are three different ways to group layers forming a cell: Cylindrical, prismatic and pouch. This classification defines the external form of cells, which may also have different sizes.

Module dimension: Cells are grouped into modules [22]. Again, we find an enormous heterogeneity in module designs. In fact, the quantity of cells per module differs between car manufacturers, between models and even for the same EV model. In fact, two different cells modules can cohabitate in the same battery pack, as it is the case of the VW e-golf.

Power and capacity: EV, Plug-in Hybrid Electric Vehicle (PHEV) and Hybrid Electric Vehicle (HEV) batteries are quite different considering power and energy capacity. Typically, EV batteries have around $24 \mathrm{kWh}$, while PHEVs are under $16 \mathrm{kWh}$ and HEV do not get above $5 \mathrm{kWh}$. Again, the power of a vehicle depends on the performance designed for the model. Nevertheless, $80 \mathrm{~kW}$ is a common value for regular EV.

Refrigeration system: High temperatures accelerate battery degradation and aging [23]. Therefore, thermal management is a major concern on EV batteries. Nowadays, car manufacturers use three options: Forced air, liquid refrigeration or natural refrigeration (none), as shown in Table 1. New alternatives, such as change-phase materials and heat pipe hybridization [24, 25 ] are expected to appear in the nearby future, although they are not yet implemented. However, liquid refrigeration systems have many specialized designs, going from simple cooling plate under the batteries to in-between cells cooling system.

Battery Management System: All batteries need electronics to control the aforementioned parameters and ensure safety and functionality. To do so, there is a particular BMS design using specific electronic equipment [26]. These BMS are nowadays prepared for first use only. These systems include complex algorithms and confidential definitions that should be guarded from foreign watchers. Besides, they also have safety instructions regarding the use on a car, such as key position or door closed among others, to prevent risks that are senseless on $2^{\text {nd }}$ life applications. In fact, due to the absence of these messages in $2^{\text {nd }}$ life applications, BMS might easily misunderstand signals and make sudden stops or give unexpected errors. 
Communication protocol: As said in the previous point, the battery management system is connected to the on-board management system, which controls the rest of the vehicle parameters. This communication is done using a Controller Area Network (CAN) protocol. Although all car manufacturers use this protocol, each one defines the messages exchanged between the batteries in a particular way. Hence, the messages for one battery model are not the same as the messages received from another model. On the other hand, batteries are expected to work alone without any need to identify their messages. That is, two batteries from the same EV model send exactly the same messages; thus, having two or more grouped batteries, there is no way to identify which messages come from which battery. Thus, some element has to be introduced in order to identify them. One last communications drawback is that, although CAN protocol is well spread in the automotive industry, it is almost inexistent for stationary applications, being Modbus and Ethernet the most commonly used protocols. More details can be found in an specialized study on EV battery $2^{\text {nd }}$ life communications accepted for publication [27].

Packaging and form: Finally, everything is packed together forming a single and safe battery. In addition to all the aspects introduced, there is the available space in the car to deal with, so batteries have to find its place along with all the other components. Therefore, there are T-shaped batteries, others occupying the complete floor of the vehicle, others with two levels, etc. Table 2 presents some of the actual batteries from different EV models, showing examples of the heterogeneity inherent in $2^{\text {nd }}$ life businesses.

Finally, battery aging is another variability factor to take into account when managing $2^{\text {nd }}$ life battery engineering [28]. Batteries are considered inappropriate for traction purposes after they have lost $20 \%$ of its capacity $[29,30]$. However, EV owners will exploit them to lower or higher depths depending on their perception of aging and their driving habits and necessities. This means that batteries arriving to the remanufacturing plant will be on an SOH range from $90 \%$ to $70 \%$ (or even below in some cases). Indeed, not all cells in a battery age in the same way under similar conditions [31] and the capacity of a battery is limited by the cell having lower performance. To estimate a battery SOH there are several tests, although there is no real consensus in how to define it. The major inconvenient is that most of them are very time consuming. According to the VDA initiative "Test specification for Li-ion battery systems", a capacity test takes up to 126 hours and a power pulse test needs 78 hours. These are long time periods for testing, which makes the $2^{\text {nd }}$ life characterization complicated and expensive. 


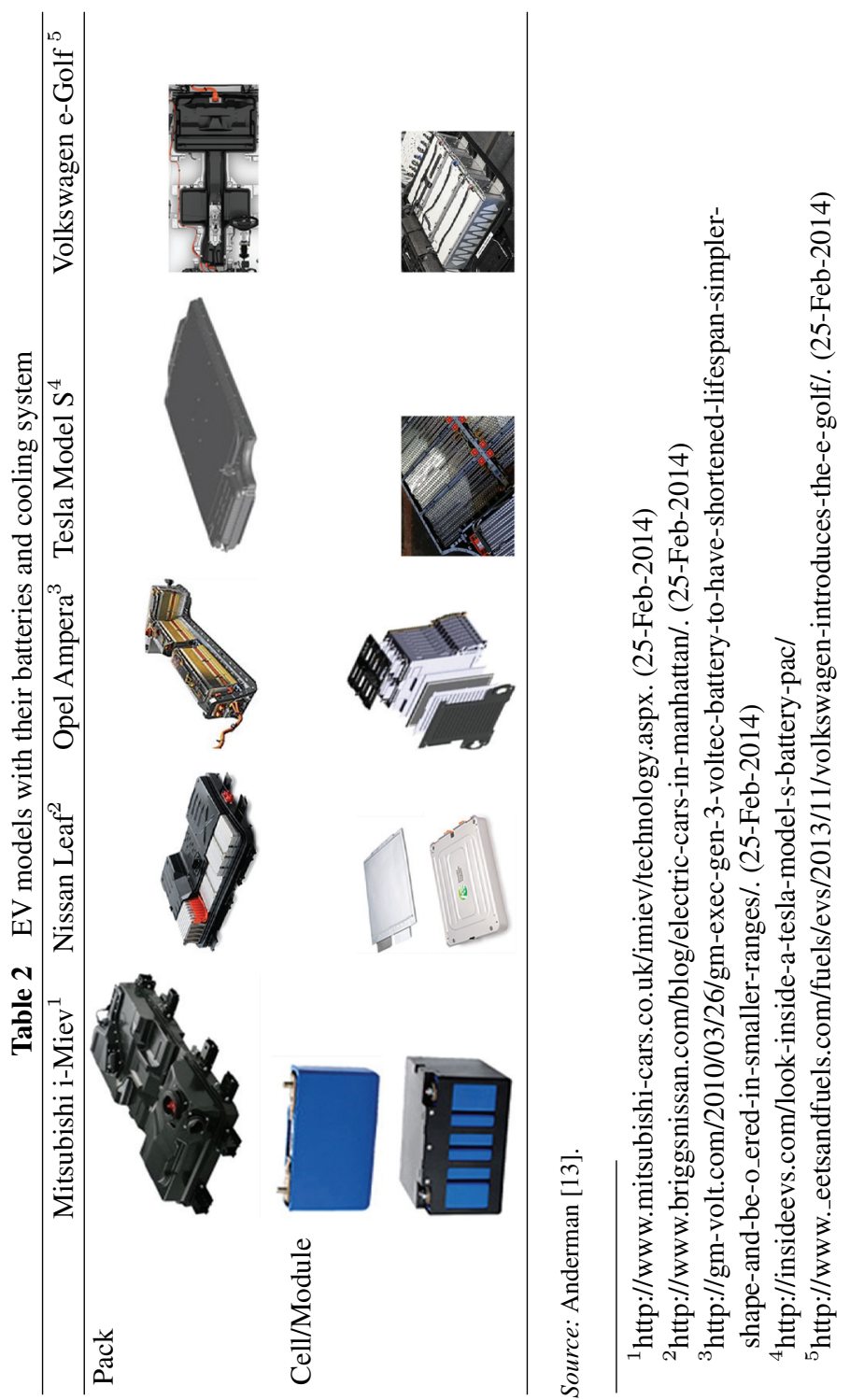




\section{Second Life Management Solutions}

This section of the study presents different solutions to confront the aforementioned situations in order to be able to manage $2^{\text {nd }}$ life EV battery businesses. Considering that EV batteries are a pack of modules, cells, electronic and cooling systems, there are two clear different strategies to follow when dealing with its preparation for reuse [32]. The First one treats a battery as the pack it is, without much more manipulation than a visual and electric check and reuses it directly. This strategy is the one selected by many car companies on their second life demonstrator projects, such as Sunbatt [33] or Batteries $2^{\text {nd }}$ Life [34] among others, where PHEV and EV batteries are installed in a maritime container to offer electricity services to the grid. The second strategy deals with the inner parts of the battery, the process consist in dismantling it into modules to regroup them again forming a new battery product better designed for $2^{\text {nd }}$ life applications. This latter option was first presented by Sandia National Laboratories in 2003 [8] and can go even further in dismantling until the cell level to afterwards refurbish a new battery [35]. These strategies are called direct reused or battery repurposing respectively.

The battery repurposing strategy requires more time and harder work to prepare a $2^{\text {nd }}$ life battery pack. Additionally, as the EV battery pack elements are dismantled, many of them are useless on the repurposed battery configuration, such as covers, cooling plates and connections between modules, producing more waste. Moreover, the new configuration will need new covers, connectors and wires, delving in a cost increase. However, the repurposed battery offers a much more flexible, optimized and fitted functional final unit. In consequence, economically speaking, previous studies presented that the direct reuse strategy may offer selling prices below $100 \$ / \mathrm{kWh}$, which can be three times lower than following the repurposing strategy [36, 37]. Moreover, considering that new battery prices are expected to decrease between 300 to $400 \$ / \mathrm{kWh}$ in the nearby future [38], the management of $2^{\text {nd }}$ life batteries following the direct reuse strategy is encouraged against the battery repurposing strategy.

After selecting the direct reuse strategy, this study analyses how to manage received batteries inside the remanufacturing plant. The study classifies the management alternatives in three categories depending on the final product and the remanufacture plant distribution: All in one, Selection and Complete specialization. Figure 3 presents a simplified overview of these alternatives to have a first clear picture of what each category represents. 

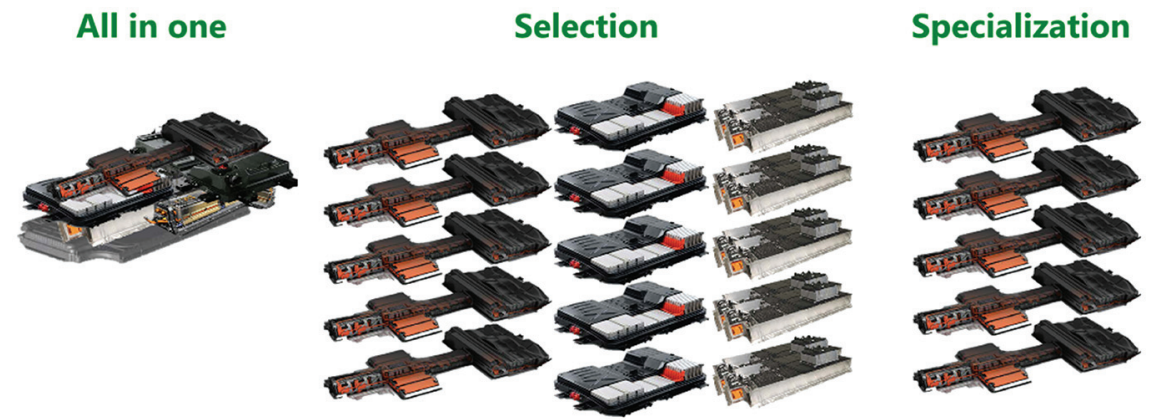

Figure 3 Different management categories for the direct reuse strategy. From left to right: All in one (Batteries packs from Tesla, Volt, I-miev, Leaf, e-golf, i3 packed together), Selection (each battery type is treated separately, in the image: e-golf, Leaf and i3 batteries) and Complete specialization (where just one battery model is accepted, e-golf battery in the image).

All in one: This option consists in the use of all type of batteries together. Nowadays, not all batteries have an $\mathrm{SOH}$ on-board estimator or an accessible message to know it, therefore, a battery functional test to assess the $\mathrm{SOH}$ and functional capacity should be executed in the remanufacturing plant. As mentioned in the final paragraph of Section 3.1, there are plenty of possible tests to do evaluate SOH: Capacity and pulse tests [39], Electrochemical Impedance Spectroscopy [40], Voltage and Temperature behaviour monitoring [41], Battery cell unbalance [42], among others. In the nearby future, this process may be accelerated by having access to the EV On-board SOH estimation algorithms. Once characterized, batteries can be prepared for a $2^{\text {nd }}$ life application or rejected if they are damaged or if their degradation is far too advanced and, thus, they are not usable for any application.

This alternative is suitable for applications with one battery only, as in autonomous or battery to home $(\mathrm{B} 2 \mathrm{H})$ applications, where energy storage requirements are similar to the EV battery dimensions [43]. On the contrary, if the preparation of multiple battery energy storage equipment is needed, which is quite provable regarding the power and capacity needs of many $2^{\text {nd }}$ life stationary applications, the biggest problems encountered will concern BMS interactions. This study considers a major assumption for all the studied cases, which is: all car manufacturers supply a communications interface or have enough confidence in the company to tell how to extract the information needed to communicate with the battery. The latter option is quite improvable because of confidentiality issues mentioned in Section 3 regarding the BMS. Moreover, the communications interface provided by each car manufacturer 
does not ensure having the same messages (as not all EV have exactly the same configuration) neither it ensures to use the same protocol. The communications on $2^{\text {nd }}$ life EV batteries is still something to evolve substantially, and nobody knows exactly how future designs will evolve. Even considering this major assumption, this alternative has the following inconveniences:

- Difficulties to predict SOH and SOC of the whole battery pack because of the variability of chemistries.

- Difficulties to charge and discharge all batteries to $100 \%$. In fact, batteries normally follow the less performing of cells and this is even more visible when mixing chemistries [44]. Hence, if there are cells with, for example, $40 \mathrm{Ah}$ and $15 \mathrm{Ah}$ capacity, when the lower capacity cell is fully discharged the battery will consider that the whole battery is completely discharged even if many other cells have still some capacity left (in this example, 25Ah from the bigger cell won't be used). Nonetheless, there are several studies presenting technologies and BMS programming that claim to manage different cell capacities [45, 46]. However, these technologies require additional electronic equipment, making batteries more expensive. Moreover, these solutions are conceived at cell level, thus, to translate it into the management of a group of batteries with different capacities, there is a need for dedicated power electronics and specific energy management systems.

- The final product will be well beyond its potential: Packaging all battery models, with its different forms and refrigeration systems into a single block would derive in plenty of empty and useless spaces. See Figure 3 left image where different EV battery models try to find its best location, as in a Tetris game. Therefore, the final result will have low power and energy density.

- Difficulties to standardize: In fact, the model and number of batteries collected will differ from one week to another because of the existing diversity in the market. Thus, working with all kind of batteries at the same time to produce a bigger battery pack trying to adjust the arrivals with the demand will originate particular developed battery packs, with specific supports, electronics and programming, for each battery order.

Even if this is not an optimal solution, it might be the first industrial step before the EV increases its market share, as it is flexible and takes profit of all the available batteries, leaving nothing to the concurrence.

Selection: This proposal also takes all possible batteries into the reusing plant, but instead of mixing them as in the previous case, batteries are classified 
according to certain characteristics. This preliminary classification eliminates most of previous impediments, such as charging efficiency, battery grouping design and standardization. However, it still depends on the major assumption that all car manufacturers will provide the BMS necessary specifications or a communications gateway to the remanufacturing enterprise. For this alternative, the use of a communications interface is preferred, as all $2^{\text {nd }}$ life batteries grouped on a remanufactured new pack will come from the same EV model and will use the same messages and protocol.

Once batteries arrive to the remanufacturing plant, the management process starts with the separation and classification by some of its characteristics. That is, for example, by battery chemistry, by cell form, by voltage range, by shape, by kWh capacity, by SOH, etc. However, a selection by model or car manufacturer directly solves almost all controversies, as an EV model will always have the same battery chemistry, shape, power, energy, cell form, refrigeration system, etc.

Then, the only diversity this classification will have is the battery $\mathrm{SOH}$. Consequently, at least a capacity and functional test should be performed to all batteries, cells and modules (depending of the battery strategy followed). This will provide a determined SOH of the battery and, therefore, the needed information to classify them in families with similar conditions for the bestsuited $2^{\text {nd }}$ life application. For example, batteries with an SOH close to $80 \%$ would go to critical services (as uninterrupted power supply or area regulation grid services), while batteries with lesser $\mathrm{SOH}$ could work on noncritical services where a battery failure implies fewer revenues but no work or information loss, such as renewable energy self-consumption.

Again, there are two alternatives to treat and select batteries depending on the industrialization process. Either they use the same production line or they have specialized lines for each type or model. Both options have pros and cons briefly discussed in Table 3 .

EV market sales will help to choose one or another solution or a mixture of them both, such as two specialized lines for the most sold cars and a flexible line to cover all other possibilities. However, Spanish EV market numbers indicate that the best-selling EV model in 2015 made only 388 units from global 2.173 sold cars. That supposes only $18 \%$ of the EV market share and almost a car per day. Considering 10 years lifetime for these batteries, which is the warranty car manufacturers are offering [47], the remanufacture plant will receive about one battery per day in 2025 . Nonetheless, EV selling tendencies and forecasts show encouraging expectations for the following years. 
Table 3 Pros and cons of battery treatment strategies

\begin{tabular}{|c|c|c|c|}
\hline \multicolumn{2}{|c|}{ Single Production Line } & \multicolumn{2}{|c|}{ Specialized Lines } \\
\hline Pros & Cons & $\overline{\text { Pros }}$ & Cons \\
\hline $\begin{array}{l}\text { Elevated working } \\
\text { rate }\end{array}$ & $\begin{array}{l}\text { Need of a huge } \\
\text { warehouse to store } \\
\text { incoming batteries }\end{array}$ & $\begin{array}{l}\text { Small warehouse, } \\
\text { fast entrance to } \\
\text { production line }\end{array}$ & $\begin{array}{l}\text { Some (most) lines } \\
\text { will be underused }\end{array}$ \\
\hline Flexible line & $\begin{array}{l}\text { Difficult } \\
\text { accessibility and } \\
\text { large or } \\
\text { exchangeable posts }\end{array}$ & Easy to manipulate & Fixed lines \\
\hline $\begin{array}{l}\text { Smaller } \\
\text { production plant }\end{array}$ & $\begin{array}{l}\text { In case of problems } \\
\text { in the line, } \\
\text { production is } \\
\text { stopped }\end{array}$ & $\begin{array}{l}\text { In case of problem } \\
\text { in one line, the } \\
\text { others will continue } \\
\text { working }\end{array}$ & $\begin{array}{l}\text { Need of a big plant } \\
\text { to include all } \\
\text { production lines }\end{array}$ \\
\hline $\begin{array}{l}\text { Production } \\
\text { adjusted to needs }\end{array}$ & $\begin{array}{l}\text { Need of an accurate } \\
\text { production program }\end{array}$ & $\begin{array}{l}\text { Less time per } \\
\text { battery }\end{array}$ & \\
\hline $\begin{array}{l}\text { Multidisciplinary } \\
\text { workers }\end{array}$ & Higher automation & $\begin{array}{l}\text { Simple and manual } \\
\text { lines }\end{array}$ & $\begin{array}{l}\text { Specialized } \\
\text { workers }\end{array}$ \\
\hline Fewer lines & $\begin{array}{l}\text { Higher investments } \\
\text { per production line }\end{array}$ & $\begin{array}{l}\text { Cheap production } \\
\text { lines }\end{array}$ & More lines \\
\hline
\end{tabular}

The quantity of batteries arriving to the factory will also determine the degree of automation. Production line posts can be either manually changeable to different battery references or they can have automated multi-reference posts. Meanwhile, specialized lines will have fixed and robust working stations, providing higher production rates, efficiency and confidence but lower capacity of adaptation. Flexibility always takes higher investments but it might also bring better results on non saturated production lines.

Complete Specialization: With such low battery numbers, and therefore, low revenues [48], some car manufacturers try to help investors to take part into the business, sharing and opening markets, like the joint venture 4Renergy $^{6}$. These joint ventures provide the possibility to investigate the gaps between client demand and battery capabilities, facilitating the entrance into business. Additionally, the involved enterprises normally sign confidential agreements offering a friendly environment and a partnership framework. Thus, the most optimistic assumption taken in the previous two solutions considering the BMS information exchange is presumably solved in this case. This alternative is the one followed in most of the $2^{\text {nd }}$ life demonstration

${ }^{6}$ http://www.4r-energy.com/en/company/ Accessed:2014/02/13 
projects, such as the aforementioned Sunbatt [33], Second Life Batteries [34], Batteries second life ${ }^{7}$ and E-mobiloty through the end ${ }^{8}$ among others. Each one of these projects is lead by a different car manufacturer and integrator or client.

This strategy comes almost with no variety; all it has to handle is $\mathrm{SOH}$ dispersion of batteries.

This solution, evidently, facilitates the plant design, the business plan accuracy (financial support) and the implementation of safety issues and internal management. Moreover, product standardization facilitates industrialization, line automation and simplifies workers' formation. On the contrary, it also leaves high potential opportunities to other concurrence initiatives. Taking the same example from the Spanish market used in the previous example, subtracting the 388 units from the most sold EV model to the 2.173 of total sold cars, we obtain that there are still 1.785 batteries from different car manufacturers to collect. In other words, $82 \%$ of the whole market is available for the concurrence.

Finally, all direct reuse alternatives have still one major drawback to overcome, which is the battery connection in series and parallel regarding security issues. In fact, each battery model has its security configuration. To present just an example, some batteries test the Isolation Voltage by forcing small power pulses between the electrodes and the battery case. This programmed routine test impedes a direct connection of batteries in series, forcing the introduction of several components to resolve it. On the other hand, when connecting them in parallel, some unexpected balancing current flows may origin between batteries having different voltage. This problem is aggravated when working with different battery models together. This is the reason why almost all demonstration projects are nowadays presented in pairs of a battery plus a converter, as presented in Figure 4. This temporary solution solves most of the problems, but needs lots of expensive power electronics. In fact, it is hard to find commercial DC/AC converters on the range of $250-400 \mathrm{~V}$ DC and 230V AC capable of offering the power that EV batteries can offer. Nowadays, these converters are designed especially for each battery type and project.

\footnotetext{
${ }^{7}$ http://www.mitsubishi-motors.com/publish/pressrelease_en/corporate/2015/news/detailf 710.html. Accessed: 31/07/2015

${ }^{8} \mathrm{http}: / /$ media.daimler.com/dcmedia/0-921-614306-1-1861874-1-0-1-0-0-1-126391549054-0-1-0-0-0-0-0.html?TS=1447166558769. Accessed: 23/11/2015)
} 

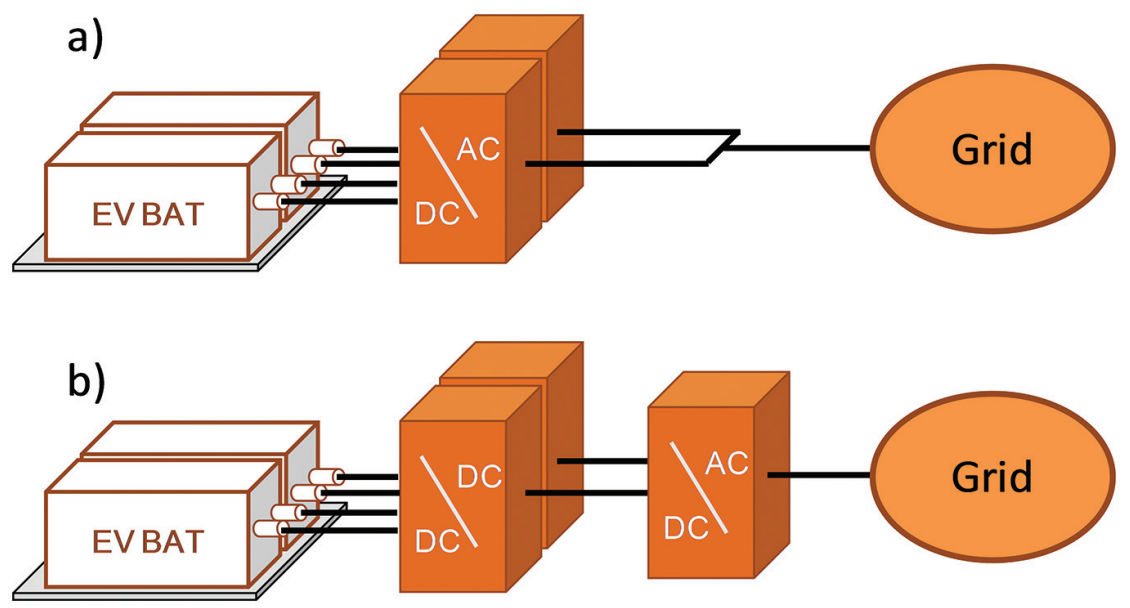

Figure 4 Schema of common $2^{\text {nd }}$ life grouped battery connections to the grid. a) By DC/DC converters directly to the grid. b) By individual DC/DC converters connected to a bigger DC/AC converter connected to the grid.

\section{Conclusions}

As all emerging markets, EV manufacturers are still testing and searching the energy storage system that better suits their needs. Therefore, many battery alternatives are being deployed. These many alternatives come with technical and business uncertainties and, consequently, with a great diversity of solutions. This study presented the principal challenges that any attempt to do business with reused batteries will face.

All the solutions presented have positive and negative aspects. The options that reuse most of batteries have more technical, formal and management difficulties, while the strategy that is focused on a battery model has industrial facilities but a smaller business market niche. The quantity of EV batteries in the collection circuit has to be taken into account when defining the business strategy in terms of automation, specialization and selection. As simplicity and standardizing is pursued by most manufacturers, at least a selection of the battery characteristics is encouraged.

Joint ventures with car manufacturers provide many facilities and reduce investment and production risks considerably, but they also leave business opportunities to concurrence.

Batteries SOH assessment tests should be improved in order to gain competitiveness for reused batteries, classifying batteries into similar conditions will help to ensure the battery pack endurance and will provide robustness. 
Communications between batteries and stationary equipment should be seriously addressed, as it is one of the principal barriers to overcome. In fact, some car manufacturers are studying the possibility to introduce two connectors (one for the $1 \mathrm{st}$ and another for the $2^{\text {nd }}$ life) or a flash memory to reprogram the BMS for a $2^{\text {nd }}$ life in the new EV battery designs.

The entrance of EVs into the automotive industry will encourage the reuse of batteries, which, at the same time, will provide economic profit that could be used to incentivize the EV market and reinforce the virtuous circle. In the end, this could lead to cleaner transportation and to an improved energy system.

\section{References}

[1] G. Tal and M. A. Nicholas, "Studying the PEV Market in California?: Comparing the PEV, PHEV and Hybrid Markets," in Electric Vehicle Symposium EVS 27, 2013, pp. 1-10.

[2] J. Anable, C. Brand, M. Tran, and N. Eyre, "Modelling transport energy demand: A socio-technical approach," Energy Policy, vol. 41, pp. 125-138, Feb. 2012.

[3] S. Carley, R. M. Krause, B. W. Lane, and J. D. Graham, "Intent to purchase a plug-in electric vehicle: A survey of early impressions in large US cites," Transp. Res. Part D Transp. Environ., vol. 18, pp. 39-45, Jan. 2013.

[4] A. Maitra, J. Taylor, M. Duvall, P. Richardson, M. Moran, and A. Keane, "Impact of Higher Power PEV Charge Levels on Three U. S. Radial System and Field Trial Findings on ESB's Low Voltage Residential Network," in Electric Vehicle Symposium EVS 27, 2013, pp. 1-12.

[5] X. Cui, H. K. Kim, C. Liu, S.-C. Kao, and B. L. Bhaduri, "Simulating the household plug-in hybrid electric vehicle distribution and its electric distribution network impacts," Transp. Res. Part D Transp. Environ., vol. 17, no. 7, pp. 548-554, Oct. 2012.

[6] B. P. Roberts and C. Sandberg, "The Role of Energy Storage in Development of Smart Grids," Proc. IEEE, vol. 99, no. 6, pp. 1139-1144, Jun. 2011.

[7] B. Price, E. Dietz, and J. Richardson, "Life cycle costs of electric and hybrid electric vehicle batteries and End-of-Life uses," 2012 IEEE Int. Conf. Electro/Information Technol., pp. 1-7, May 2012.

[8] E. Cready, J. Lippert, J. Pihl, I. Weinstock, P. Symons, and R. G. Jungst, "Technical and Economic Feasibility of Applying Used EV Batteries in Stationary Applications A Study for the DOE Energy Storage Systems Program," Albuquerque, 2003. 
[9] L. Canals Casals, B. Amante García, and M. González Benítez, "Segundas vidas para baterías de coches eléctricos?: buenas ideas - malos negocios," DYNA Ing. e Ind., vol. 89, pp. 46-49, 2014.

[10] M. D. Farrington, "Safety of lithium batteries in transportation," J. Power Sources, vol. 96, no. 1, pp. 260-265, 2001.

[11] IATA, "Lithium Battery Guidance Document," 2014.

[12] Marco Ottaviani, Lithium batteries: transportation and packaging instructions. 2015.

[13] M. Anderman, "Assessing the Future of Hybrid and Electric Vehicles: The xEV Industry Insider Report," 2014.

[14] S. Huang, B. M. S. Hodge, F. Taheripour, J. F. Pekny, G. V. Reklaitis, and W. E. Tyner, "The effects of electricity pricing on PHEV competitiveness," Energy Policy, vol. 39, no. 3, pp. 1552-1561, 2011.

[15] C. S. N. Shiau, C. Samaras, R. Hauffe, and J. J. Michalek, "Impact of battery weight and charging patterns on the economic and environmental benefits of plug-in hybrid vehicles," Energy Policy, vol. 37, no. 7, pp. 2653-2663, 2009.

[16] D. Chung, E. Elgqvist, and S. Santhanagopalan, "Automotive Lithium ion Battery (LIB) Supply Chain and U.S. Competitiveness Consideraions," Clean Energy Manuf. Anal. Cent., no. June, pp. 1-41, 2015.

[17] C. Cluzel and C. Douglas, "Cost and performance of EV batteries," 2012.

[18] C. Hou, H. Wang, and M. Ouyang, "Battery sizing for plug-in hybrid electric vehicles in Beijing: A TCO model based analysis," Energies, vol. 7, no. 8, pp. 5374-5399, 2014.

[19] A. Eddahech, O. Briat, and J. M. Vinassa, "Performance comparison of four lithium-ion battery technologies under calendar aging," Energy, vol. 84, pp. 542-550, 2015.

[20] R. Teodorescu, D. U. Sauer, P. Rodriguez, M. Swierczynski, and P. Doc, Industrial/PhD Course Storage Systems based on Electrochemical Batteries for Grid Support Applications. Aalborg: Aalborg University, Denmark, 2013.

[21] J. Vetter, P. Nov, M. R. R. Wagner, C. Veit, P. Novák, K.-C. Möller, J. O. Besenhard, M. Winter, M. Wohlfahrt-Mehrens, C. Vogler, and A. Hammouche, "Ageing mechanisms in lithium-ion batteries," J. Power Sources, vol. 147, no. 1-2, pp. 269-281, Sep. 2005.

[22] M.-H. Yang, "Predicting Heat release to prevent thermal runaway propagation and achieving long term EV li-ion battery safety," in Electric Vehicle Battery Forum, 2011. 
[23] T. Waldmann, M. Wilka, M. Kasper, M. Fleischhammer, and M. Wohlfahrt-Mehrens, "Temperature dependent ageing mechanisms in Lithium-ion batteries - A Post-Mortem study," J. Power Sources, vol. 262, pp. 129-135, Sep. 2014.

[24] Z. Rao and S. Wang, "A review of power battery thermal energy management," Renew. Sustain. Energy Rev., vol. 15, no. 9, pp. 4554-4571, Dec. 2011.

[25] X. Duan and G. F. Naterer, "Heat transfer in phase change materials for thermal management of electric vehicle battery modules," Int. J. Heat Mass Transf., vol. 53, no. 23-24, pp. 5176-5182, Nov. 2010.

[26] J. Cao and A. Emadi, "Batteries Need Electronics," IEEE Ind. Electron. Mag., vol. 5, no. 1, pp. 27-35, 2011.

[27] L. Canals Casals and B. Amane García, "Communications concerns for reused electric vehicle batteries in smart grids.," IEEE Commun. Mag., pp. 1-10, 2016.

[28] M. Broussely, P. Biensan, F. Bonhomme, P. Blanchard, S. Herreyre, K. Nechev, and R. J. Staniewicz, "Main aging mechanisms in Li ion batteries," J. Power Sources, vol. 146, no. 1-2, pp. 90-96, Aug. 2005.

[29] A. Eddahech, O. Briat, and J.-M. Vinassa, "Determination of lithium-ion battery state-of-health based on constant-voltage charge phase," J. Power Sources, vol. 258, pp. 218-227, Jul. 2014.

[30] V. V. Viswanathan and M. Kintner-Meyer, "Second Use of Transportation Batteries: Maximizing the Value of Batteries for Transportation and Grid Services," in IEEE Transactions on Vehicular Technology, 2011, vol. 60, no. 7, pp. 2963-2970.

[31] P. Leijen, "Real World Battery Diagnostics Model Based and Prius Case Study," in IEEE 23rd International Symposium on Industrial Electronics (ISIE), 2014, no. 3, pp. 2457-2462.

[32] L. Canals Casals and B. Amante García, "A review of the complexities of applying second life electric car batteries on energy businesses," in Energy Systems Conference, 2014.

[33] H. Cruz Gibert, M. Cruz Zambrano, L. Canals Casals, S. Castella Daga, and P. Diaz Pinos, "Sunbatt: Use of a Second Life Battery System from PHEV in Stationary Applications," in Smart City Expo World Congress, 2015.

[34] B. Gohla-Neudecker, M. Bowler, and S. Mohr, "Battery 2nd life: Leveraging the sustainability potential of EVs and renewable energy grid integration," in 5th International Conference on Clean Electrical Power: Renewable Energy Resources Impact, ICCEP 2015, 2015, pp. 311-318. 
[35] S. J. Tong, A. Same, M. a. Kootstra, and J. W. Park, "Off-grid photovoltaic vehicle charge using second life lithium batteries: An experimental and numerical investigation," Appl. Energy, vol. 104, pp. 740-750, Apr. 2013.

[36] F. Carranza, "Second life of Li-batteries used in EV," in Advanced Workshop: New challenges in Li-Batteries materials and components for EVs., 2013.

[37] L. Canals Casals, M. González Benítez, and B. Amante García, "A cost analysis of electric vehicel battery second life businesses," in XVIII International congress on project management and engineering, 2014, pp. 0946-0958.

[38] J. Neubauer, A. Pesaran, B. Williams, M. Ferry, and J. Eyer, “A Technoeconomic analysis of PEV battery second use_repurposed battery selling price and commercial and industrial end_user value," in SAE World Congress and Exhibition, 2012.

[39] S. Thanagasundram, R. Arunachala, K. Makinejad, T. Teutsch, and A. Jossen, "A Cell Level Model for Battery Simulation," in European Electric Vehicle Congress, 2012, no. November, pp. 1-13.

[40] D. Stroe, M. Swierczynski, A.-I. Stan, and R. Teodorescu, "Accelerated lifetime testing methodology for lifetime estimation of Lithium-ion batteries used in augmented wind power plants," 2013 IEEE Energy Convers. Congr. Expo., pp. 690-698, Sep. 2013.

[41] A. Zenati, P. Desprez, H. Razik, and S. Rael, "A Methodology to Assess the State Of Health of Lithium-ion Batteries Based on the Battery's Parameters and a Fuzzy Logic System," in Electric Vehicle Conference (IEVC), 2012.

[42] H. J. Khasawneh and M. S. Illindala, "Battery cycle life balancing in a microgrid through flexible distribution of energy and storage resources," J. Power Sources, vol. 261, no. 2014, pp. 378-388, Sep. 2014.

[43] B. Andrew, "Performance, charging and second use considerations for lithium batteries for plug-in electric vehicles," in The electricity storage association meeting, session on transportation and grid, 2009.

[44] A. C. Karl VESTIN, "Networked Battery Management System, A novel and efficient approach to Management of large battery systems," in Advanced Workshop: New challenges in Li-batteries materials and components for EVs (SOMABAT), 2013.

[45] M. Daowd, N. Omar, P. Van Den Bossche, and J. Van Mierlo, "Passive and active battery balancing comparison based on MATLAB simulation," in 2011 IEEE Vehicle Power and Propulsion Conference, VPPC 2011, 2011. 
[46] M. Einhorn, W. Guertlschmid, T. Blochberger, R. Kumpusch, R. Permann, F. V. Conte, C. Kral, and J. Fleig, "A current equalization method for serially connected battery cells using a single power converter for each cell," IEEE Trans. Veh. Technol., vol. 60, no. 9, pp. 4227-4237, 2011.

[47] D. Strickland, L. Chittock, D. a. Stone, M. P. Foster, and B. Price, "Estimation of Transportation Battery Second Life for Use in Electricity Grid Systems," IEEE Trans. Sustain. Energy, pp. 1, 2014.

[48] P. Ciccioni, D. Landi, Alessandro Morbidoni, and M. Germani, "Feasability analysis of second life applications for li-ion cells used in electric powertrain using environmental indicators.," in 2nd IEEE ENERGYCON Conference \& Exhibition, Sustainable Transportation Systems Symp, 2012, pp. 985-990.

\section{Biographies}

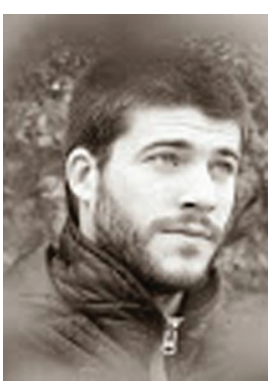

Ll. Canals Casals finished his master degree in industrial engineering in 2005 at the Universitat Politècnica de Catalunya and, after some years working in the automotive industry, he returned to the Universitat Politècnica de Catalunya where he became Doctor in 2016 working on electric vehicle batteries' second life and ageing. 


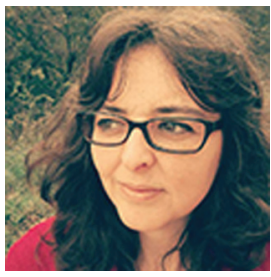

B. Amante García was born in Alicante (Spain). She has a PhD in Telecommunications by the École nationale supérieure des télécommunications of Paris. She is nowadays working at the Universitat Politècnica de Catalunya in the Projects Engineering Department. She started her teaching career focusing on the fields of electronics, radio systems and Engineering projects. During these last years she started the study of battery ageing. 